Research Article

\title{
Eco-Friendly Adsorbent from Waste of Mint: Application for the Removal of Hexavalent Chromium
}

\author{
Fatima Khammour $\mathbb{D D}^{1}$ Fatouma Mohamed Abdoul-Latif $\mathbb{D}^{2},{ }^{2}$ Ayoub Ainane $\mathbb{D}$, 1 \\ Jalludin Mohamed, ${ }^{2}$ and Tarik Ainane $\mathbb{C}^{1}$ \\ ${ }^{1}$ Superior School of Technology - Khenifra (EST-Khenifra), University of Sultan Moulay Slimane, BP 170, \\ Khenifra 54000, Morocco \\ ${ }^{2}$ Medicinal Research Institute, Center for Research and Study of Djibouti, BP 486, Djibouti, Djibouti
}

Correspondence should be addressed to Fatima Khammour; fatimakhammour@gmail.com and Ayoub Ainane; ainane.ayoub@ gmail.com

Received 2 September 2020; Revised 29 March 2021; Accepted 8 April 2021; Published 22 April 2021

Academic Editor: Liviu Mitu

Copyright (c) 2021 Fatima Khammour et al. This is an open access article distributed under the Creative Commons Attribution License, which permits unrestricted use, distribution, and reproduction in any medium, provided the original work is properly cited.

\begin{abstract}
A serious environmental disaster is looming on the horizon due to the indiscriminate release of heavy metals into the soil and wastewater from human industrial practices. In this study, waste mint (WM) was used to remove chromium(VI) from aqueous solution using batch experiments. The adsorbent material (WM) was characterized using scanning electron microscopy coupled with energy dispersive analysis of X-ray spectroscopy (SEM-EDS), Fourier transform infrared spectroscopy (FTIR), differential scanning calorimetry (DSC), and thermal gravimetric analysis (TGA). The adsorption parameters optimized were as follows: $\mathrm{pH}$ solution (2-11), initial concentration of $\mathrm{Cr}(\mathrm{VI})(10-50 \mathrm{mg} / \mathrm{L})$, adsorbent dose $(0.1-10 \mathrm{~g} / \mathrm{L})$, and temperature conditions $(298 \mathrm{~K}$, $308 \mathrm{~K}$, and $318 \mathrm{~K})$. The experimental data fitted well to the fractional power kinetic model $\left(0.97 \leq R^{2} \leq 0.99\right)$ and Langmuir isotherm $\left(R^{2}=0.984\right)$ with a maximum adsorption capacity $Q_{\max }=172.41 \mathrm{mg} / \mathrm{g}$. The thermodynamic parameters for $\operatorname{Cr}(\mathrm{VI})$ sorption were also calculated, confirming that the adsorption process was spontaneous and accompanied by an exothermic adsorption ( $-4.83 \leq$ $\Delta \mathrm{G} \leq-3.22 \mathrm{~kJ} / \mathrm{mol}$ and $\Delta \mathrm{H}=-28.93 \mathrm{~kJ} / \mathrm{mol}$ ). The $\mathrm{Cr}(\mathrm{VI})$ removal percentage was within the range of $41-98 \%$, and the highest removal was noted at $\mathrm{pH}=2$. The results of the present study suggest that WM is a potential low-cost adsorbent for the removal of chromium(VI) from aqueous solutions.
\end{abstract}

\section{Introduction}

The growing demand for adsorbents used in environmental protection processes has made their price more expensive, prompting further research for the manufacture of new, less expensive absorbent materials from plant waste. From its discovery, mint is used as a medicinal and aromatic plant. In Morocco, mint cultivation is practiced everywhere, on small plots almost at the level of all farms, so spearmint is available throughout the year, and the yield is 4 to 6 tonnes of dry matter per hectare and per cut [1]. Different household waste treatment channels aim to recover waste, including in agriculture and breeding and particularly in environmental applications, especially in wastewater treatment. The presence of heavy metals in the environment is a major concern due to their toxicity to many life forms on the planet. Unlike organic pollutants, which are mostly biologically degradable, heavy metals do not degrade into harmless end-products [2]. The metals of greatest concern are $\mathrm{Cr}, \mathrm{Mn}, \mathrm{Fe}, \mathrm{Zn}$, and $\mathrm{Cd}$, which are widely distributed in the materials that make up the Earth's surface. Among these heavy metals, chromium is found in higher concentrations in wastes from electroplating, paints, dyes, leather tanning, paper mills, and many other industries [3, 4]. Chromium VI is classified as certain carcinogenic to humans but only during exposure by inhalation (Arab et al., 2014). In humans, the associated cancer is that of the lungs. Some data also assume an increase in nasal and sinus cancers, and chronic 
exposure to chromium VI via drinking water causes gastrointestinal (mouth ulcerations, diarrhea, abdominal pain, dyspepsia, and vomiting) and haematological (anemia and leukocytosis) effects and immature neutrophils [5]. For workers exposed to chromium via air, the main effects observed relate to the respiratory system (irritation of the nasal mucosa, asthma, cough, shortness of breath, and wheezing) and the development of allergies to chromium. These effects have been confirmed in animals [6]. This metal is extremely toxic; therefore, exposure to high concentration of chromium can cause an epigastric pain, nausea, vomiting, severe diarrhea, and hemorrhage [7]. The maximum level of chromium in drinking water must not exceed $0.05 \mathrm{mg} / \mathrm{L} \mathrm{[8].}$ To remove heavy metal ions dissolved in wastewater, several techniques such as solvent extraction, ion exchange, membrane process, electrodialysis, precipitation, phytoextraction, ultrafiltration, reverse osmosis, and adsorption have been tested [9]. With the exception of adsorption, those methods are not economically viable and have some disadvantages, such as incomplete removal of metals, high cost of reagents, and energy requirements, and also, it can product a toxic sludge or other wastes requiring further disposal or treatment [10]. Adsorption is generally the most preferred method for the removal of heavy metal ions due to its high efficiency, easy handling, availability of different adsorbents, and cost-effectiveness [11]. Many investigations have been carried out on the effective removal of heavy metals from solution using natural adsorbents derived from household wastes [12-16]. The purpose of this study is therefore to investigate the possible use of mint waste, a household waste, for the removal of chromium ions from aqueous solution.

\section{Materials and Methods}

2.1. Reagents. The entire reagents used in this work were of high grade. Stock solutions of the chromium metal ions were prepared by dissolving $\mathrm{K}_{2} \mathrm{Cr}_{2} \mathrm{O}_{7}$ in bidistilled water. All the aqueous solutions were prepared using bidistilled water which was chrome free.

2.2. Preparation of Adsorbent. The waste mint (Mentha spicata) was collected from the discharge of the cafeteria in Hassan II University (Casablanca, Morocco). The collected materials were washed several times with boiled water and finally with distilled water to remove any adhering dirt. The washed materials were then dried in the oven at $60^{\circ} \mathrm{C}$ for $72 \mathrm{~h}$. The dried biomass was then ground and sieved to obtain the particle size in the range of $250-500 \mu \mathrm{m}$. No other chemical or physical treatments were applied to the support. Finally, the resulting product was stored in an air-tight container for further use.

2.3. Characterization of Adsorbent. Scanning electron microscope coupled to energy dispersive analysis of $\mathrm{X}$-ray spectroscopy (SEM-EDS, JSM-5800; JEOL CO., Tokyo, Japan) was used in order to determine the surface morphology and the elementary compositions of the adsorbent (WM).
Fourier transform infrared (FTIR) spectrum of the sample was recorded by the Fourier transform infrared spectrophotometer (FTIR, BRUKER VERTEX 70, Billerica, USA), ranged from 4000 to $400 \mathrm{~cm}^{-1}$ at a resolution of $4 \mathrm{~cm}^{-1}$, from which the functional groups of the adsorbent were determined.

The thermal analysis: differential scanning calorimetry (DSC) and thermal gravimetric analysis (TGA) of the adsorbent, was done using thermal analyzer (Linseis Stapt1600 , Germany), and the temperature range was from 0 to $1000^{\circ} \mathrm{C}$ at a heating rate of $10^{\circ} \mathrm{C} / \mathrm{min}$.

2.4. Apparatus and Instruments for Adsorption. Every equipment used was soaked in concentrated $\mathrm{HNO}_{3}$ for $12 \mathrm{~h}$ and then washed initially with tap water and then with distilled water. Then, the equipment was dried in a hot air oven. A digital $\mathrm{pH}$ meter (W\&W) was used for all $\mathrm{pH}$ measurements. A high-precision electrical balance was used for weighing. All absorbance measurements were carried out with a spectrophotometer (Shidmadzu Model UV-1601, Kyoto, Japan) equipped with $1 \mathrm{~cm}$ quartz cells.

2.5. Analysis of Chromium(VI) Ions. The residual concentration of $\mathrm{Cr}(\mathrm{VI})$ ions in the effluent has been determined using diphenyl carbazide as a complexing agent: one milliliter of diphenyl carbazide solution $(0.2 \%(\mathrm{w} / \mathrm{v}))$ prepared in $95 \%$ acetone and $1 \mathrm{~mL}$ of $1 / 5 \mathrm{H}_{2} \mathrm{SO}_{4}$ solution was added to the sample $(1 \mathrm{~mL})$ containing less than $100 \mathrm{mg} / \mathrm{L}$ of $\mathrm{Cr}(\mathrm{VI})$. The absorbance of the purple-colored solution was read at $540 \mathrm{~nm}$ after $10 \mathrm{~min}$ [17].

2.6. Batch Sorption Experiments. Adsorption studies were carried out using the batch technique to obtain rate and equilibrium data. The effects of various parameters on the rate of adsorption process were studied by varying initial $\mathrm{pH}$ solution (2-11), initial chromium ion concentration $\left(\mathrm{C}_{0}\right.$ : 10-50 mg/L), adsorbent mass (W: $0.1-10 \mathrm{~g} / \mathrm{L}$ ), and temperature of adsorption ( $\mathrm{T}: 298-318 \mathrm{~K}$ ).

The experiments were performed in a thermal shaker using $250 \mathrm{~mL}$ beakers containing $100 \mathrm{~mL}$ of different chromium(VI) concentrations. Continuous mixing was provided during the experimental period with a constant agitation speed for better mass transfer to obtain a high interfacial area of contact. The remaining concentration of chromium in each sample (after the adsorption test) was determined by using a spectrophotometer after filtering the adsorbent with Whatman filter paper to make it WM free. The $\mathrm{pH}$ of the solution was adjusted to the required value by adding either dilute $\mathrm{H}_{2} \mathrm{SO}_{4}$ or $\mathrm{NaOH}$ solutions. The $\mathrm{Cr}(\mathrm{VI})$ concentration retained in the adsorbent phase was calculated according to the following equation[18]:

$$
q=\frac{\left(C_{0}-C_{e}\right)}{W}
$$

where $C_{0}$ and $C_{e}$ are the initial and equilibrium concentrations $(\mathrm{mg} / \mathrm{L})$ of $\mathrm{Cr}(\mathrm{VI})$ solution, respectively, and $\mathrm{W}$ is the weight of the adsorbent $(\mathrm{g} / \mathrm{L})$. 
The percentage removal of dye was calculated as follows:

$$
\text { removal percentage }=\left(\frac{C_{0}-C_{e}}{C_{0}}\right) \times 100 .
$$

To increase the accuracy of the data, each experiment was repeated 3 times, and the average value was reported.

2.7. Kinetic, Isotherm, and Thermodynamic Studies and Modeling. Fractional power, pseudo-first order, pseudosecond order, Elovich, and intraparticle diffusion rate equations have been used in order to model the kinetics of chromium(VI) adsorption [19, 20].

To investigate the interaction between the amount absorbed and the chromium concentration at equilibrium, we used the theoretical models described in [21, 22].

Thermodynamic parameters, including the Gibbs-free energy $\left(\Delta G^{\circ}\right)$, enthalpy $\left(\Delta H^{\circ}\right)$, and entropy $\left(\Delta S^{\circ}\right)$, are the actual indicators for practical application of an adsorption process. According to the values of these parameters, the processes that occur spontaneously can be determined. The thermodynamic parameters were determined using the following equations [23]:

$$
\begin{aligned}
\Delta G^{\circ} & =\Delta H^{\circ}-T \Delta S^{\circ}, \\
K & =\frac{Q_{e}}{C_{e}}, \\
L n(K) & =\frac{\Delta S^{\circ}}{R}-\frac{\Delta H^{\circ}}{R \cdot T},
\end{aligned}
$$

where $K, Q_{e}, C_{e}, R$, and $T$ are the equilibrium constant, the amount of the metal adsorbed at equilibrium (mol/L), the equilibrium concentration of metal $(\mathrm{mol} / \mathrm{L})$, the gas constant $(8.314 \mathrm{~J} / \mathrm{mol} . \mathrm{K})$, and the absolute temperature (Kelvin), respectively. By plotting a graph of $\ln K$ versus $1 / T$, the values $\Delta H^{\circ}$ and $\Delta S^{\circ}$ can be estimated from the slopes and intercepts.

2.8. Preprocessing of Adsorbent and Adsorption Process. The experimental procedures are shown in Figure 1.

\section{Results and Discussion}

\subsection{Characterization of the Adsorbent}

3.1.1. SEM-EDS Studies. The scanning electron microscope (SEM) images shown in Figure 2 revealed the morphological nature of the piece of waste $\operatorname{mint}(0.5 \mathrm{~cm} \times 0.5 \mathrm{~cm})$ at the resolution of $50 \mu \mathrm{m}$ (Figure $2(\mathrm{a})$ ) and $10 \mu \mathrm{m}$ (Figure 2(b)).

The results obtained show, on the one hand, an irregular and porous structure and, on the other hand, a heterogeneity of the pores shapes over the whole surface of the WM. This result encourages the evaluation of this waste as an adsorbent in the treatment of chromium-polluted water. Furthermore, the microanalysis by energy dispersive analysis of $\mathrm{X}$-ray spectroscopy (EDX) of this surface gives a chemical composition as functions of mass percentages as it listed in Table 1.
The results show a high percentage of carbon (C) and oxygen $(\mathrm{O})$, which is consistent with the organic nature of the support.

3.1.2. FTIR Spectroscopy. Figure 3 illustrates the FTIR spectrum of MM. The broad band in the region around $3425 \mathrm{~cm}^{-1}$ is attributed to the surface hydroxyl groups of the bonded carboxylic acid. The $\mathrm{O}-\mathrm{H}$ stretching vibrations occurred within a broad range of frequencies indicating the presence of free hydroxyl groups and bonded $\mathrm{O}-\mathrm{H}$ bands of carboxylic acid. The asymmetric $\mathrm{C}-\mathrm{H}$ stretching of the methyl surface groups usually present on the lignin structure is observed at $2920 \mathrm{~cm}^{-1}$. The characteristic peaks of C-O group in the carboxylic and alcoholic groups were found at 1050 and $1033 \mathrm{~cm}^{-1}$. The ionisation of the carboxylic acid and hydroxyl functional groups present in the structure of the adsorbent can be obtained by deprotonation, which allows it to interact easily with metals, and can therefore constitute the main adsorption sites for the removal of $\mathrm{Cr}(\mathrm{VI})$ ions from solutions. The $-\mathrm{OH},-\mathrm{NH}$, carbonyl, and carboxylic groups have been reported as very important sorption sites for metal ions $[24,25]$.

3.1.3. TGA and DSC Studies. The DSC and TGA result curves are shown in Figures 4 and 5 . The thermal changes in the WM can be observed during heating. The DSC curve shows a peak of endothermic transformation at $136.17^{\circ} \mathrm{C}$, which explains the evaporation of water molecules and also the fusion of the organic molecules that have remained in the waste mint. These results, after the thermal transformation, were confirmed by the TGA curve which gives a water loss of the WM of $7.8 \%$ ( $86.4 \%$ decomposable before $\left.200^{\circ} \mathrm{C}\right)$, in addition to the $5.9 \%$ related to the residues of the $\mathrm{WM}$ left during heating to $1000^{\circ} \mathrm{C}$. Based on these results, we can suggest that the WM material can be used for adsorption experiments at temperatures below $100^{\circ} \mathrm{C}$, as no thermal changes will be detected in this range.

\subsection{Effect of Various Adsorption Parameters}

3.2.1. Effect of Solution $p H$. The $\mathrm{pH}$ effect on the adsorption process was investigated by undertaking the batch adsorption technique at different hydrogen ion concentrations while maintaining the other parameters constant at $T=298 \mathrm{~K}, t=120 \mathrm{~min}, m=2 \mathrm{~g} / \mathrm{L}$, and $C_{\mathrm{i}}=50 \mathrm{mg} / \mathrm{L} \mathrm{Cr}(\mathrm{VI})$. The $\mathrm{pH}$ of the adsorption medium was varied between 2 and 11 , and the adsorbent (WM) gave the highest performance of $76 \%$ at the $\mathrm{pH}=2$ (Figure 6). The maximum performance was obtained at $\mathrm{pH}=2$, and hence, all the other experiments were carried at this $\mathrm{pH}$ value. In aqueous solutions, $\mathrm{Cr}(\mathrm{VI})$ exists in several stable forms such as $\mathrm{CrO}_{4}{ }^{2-}, \mathrm{HCrO}_{4}{ }^{-}$, and $\mathrm{Cr}_{2} \mathrm{O}_{7}{ }^{2-}$ [26]. In the range of maximum adsorption $\mathrm{pH}$, the dominant species was reported to be $\mathrm{HCrO}_{4}{ }^{-}$. The chemical nature of the functional groups in waste mint (WM) can be modified by changes in the $\mathrm{pH}$ of the adsorption medium and subsequently increasing the sorption capacity of the metals in the adsorbents [27]. 


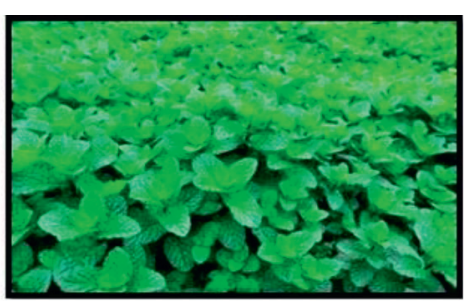

Waste of mint (WM)

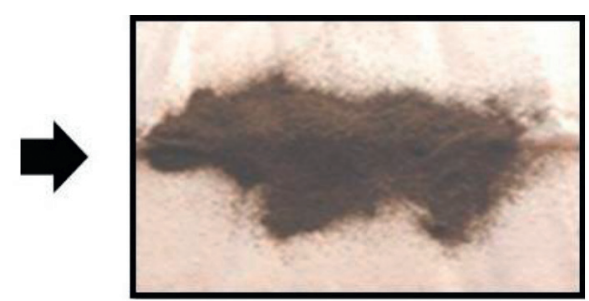

Adsorbent WM prepared

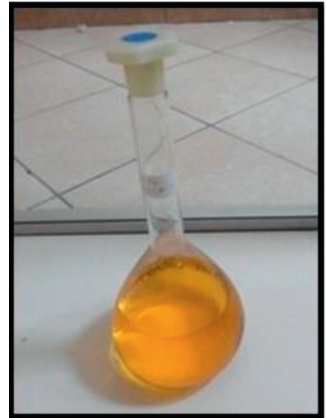

Chromium VI solution



Adsorption process

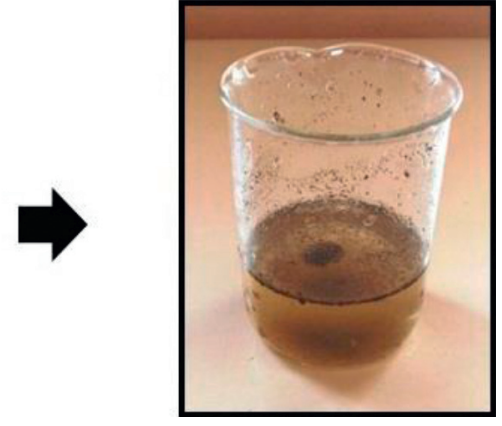

Removel of chromium(VI) from aqueous solution using WM

FIgURE 1: Preprocessing of adsorbent and adsorption process.


Figure 2: SEM images of the WM adsorbent: (a) $50 \mu \mathrm{m}$; (b) $10 \mu \mathrm{m}$.

Table 1: Percent for major atomic composition determined by EDX.

\begin{tabular}{lcccc}
\hline Composition & $\mathrm{C}$ & $\mathrm{O}$ & $\mathrm{N}$ & Other elements \\
\hline Percentage content (\%) & 66.33 & 21.84 & 4.63 & 6.2 \\
\hline
\end{tabular}

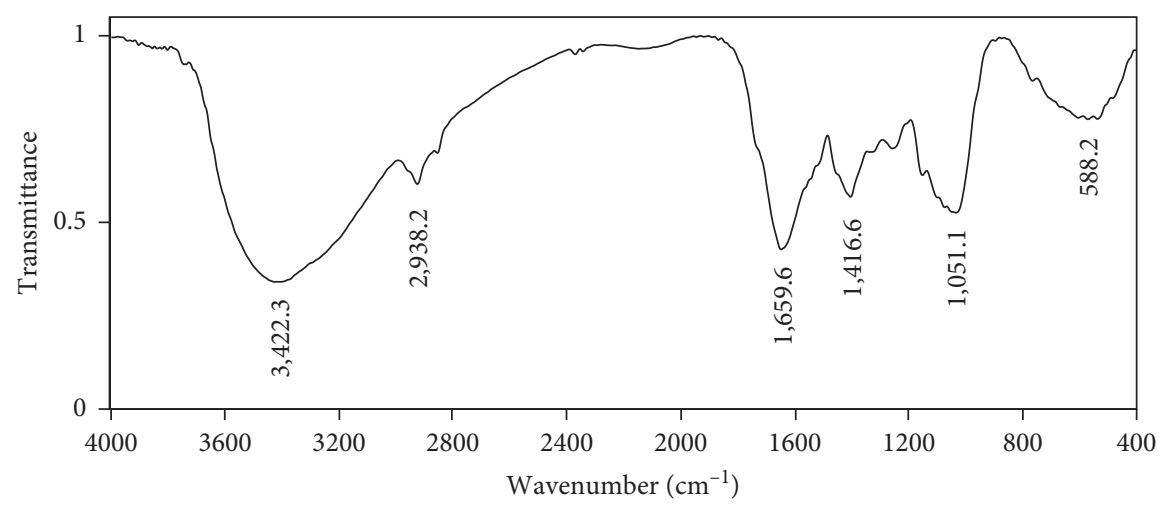

FIgURe 3: FTIR spectra of WM. 




FIgURe 4: TGA for WM.

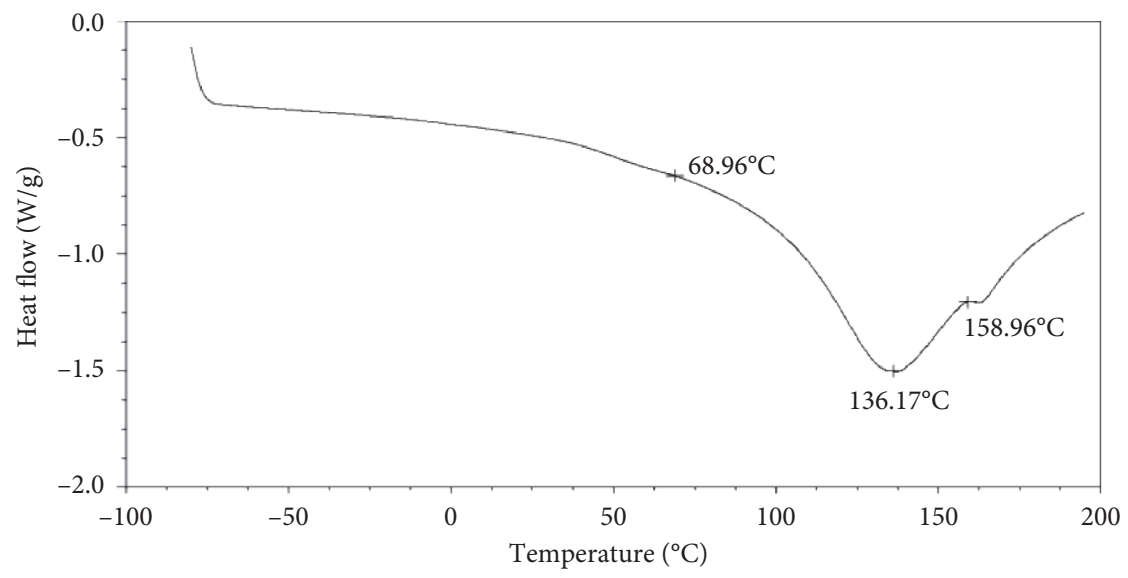

FIgURE 5: DSC for WM.

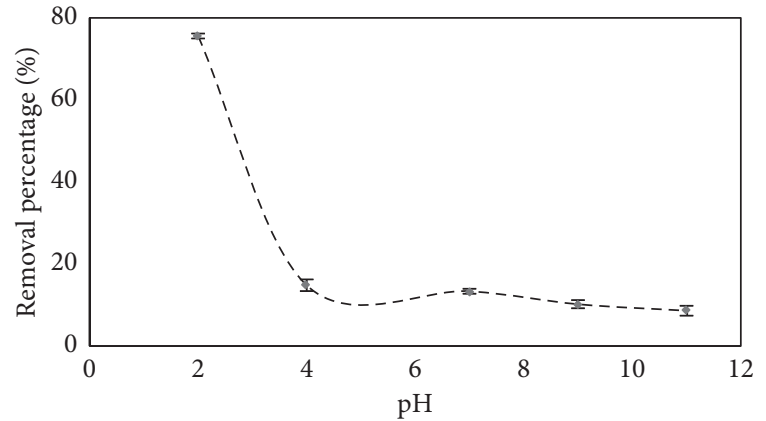

Figure 6: Effect of $\mathrm{pH}$ on the adsorption of $\mathrm{Cr}(\mathrm{VI})$ ions from aqueous solution using $\mathrm{WM}$ adsorbent at $T=298 \mathrm{~K}$, time$=120 \mathrm{~min}$, adsorbent dose $W=2 \mathrm{~g} / \mathrm{L}$, and $[\mathrm{Cr}(\mathrm{VI})]=50 \mathrm{mg} / \mathrm{L}$.

There was reported competition for the same sorption sites with metal ions by hydrogen ions at low $\mathrm{pH}$ values, and it is therefore suggested that the sites of adsorption on the surface of the WM are taken up by hydrogen ions $\left(\mathrm{H}^{+}\right)$, making the surface positively charged. Then, the negatively charged ions $\mathrm{HCrO}^{-}$ will approach and spontaneously access the binding sites on the adsorbent in order to pick up the more important metal ions due to the electrical attraction with the positive sites generated by the $\mathrm{H}^{+}[28]$.
3.2.2. Effect of $\mathrm{Cr}(V I)$ Initial Concentration. The performance effectiveness of WM has been studied at different initial concentrations of hexavalent chromium of 10, 20, 30, 40 , and $50 \mathrm{mg} / \mathrm{L}$ (Figure 7), while keeping other parameters constant. The adsorption efficiency decreases with increasing concentration of $\mathrm{Cr}(\mathrm{VI})$ ions, and it is noted that the removal percentage has a maximum value of $90 \%$ for the initial chromium concentration of $10 \mathrm{mg} / \mathrm{L}$. The explanation of this phenomenon is that when the concentration of $\mathrm{Cr}(\mathrm{VI})$ is high enough, the surface of the adsorbent is occupied and the efficiency starts to decrease, and therefore, the molecules desorb from the adsorbent surface.

3.2.3. Effect of Adsorbent Dosage. Figure 8 shows that the percentage removal of hexavalent chromium from the MW increased from $11 \%$ to $98 \%$ as the adsorbent dosage increased from 0.1 to $10 \mathrm{~g} / \mathrm{L}$. This is attributed to the increase in adsorption area and the availability of more adsorption sites.

3.2.4. Effect of Temperature. The temperature effect on the removal of $\mathrm{Cr}(\mathrm{VI})$ ions by $\mathrm{MW}$ was studied at three temperatures: $298 \mathrm{~K}, 308 \mathrm{~K}$, and $318 \mathrm{~K}$, as shown in Figure 9. The maximum adsorption capacity was obtained at $298 \mathrm{~K}$ for a 


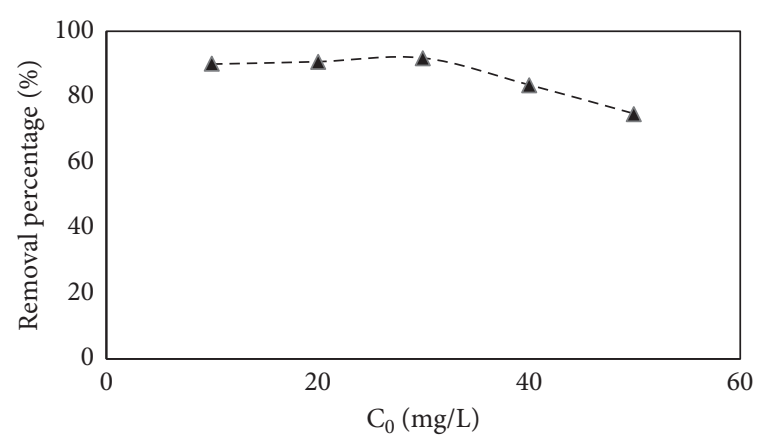

Figure 7: Effect of $\mathrm{Cr}(\mathrm{VI})$ concentration on the adsorption rate from aqueous solution using WM adsorbent at $T=298(\mathrm{~K}), \mathrm{pH}=2$, time $=120 \mathrm{~min}$, and adsorbent dose $W=2 \mathrm{~g} / \mathrm{L}$.

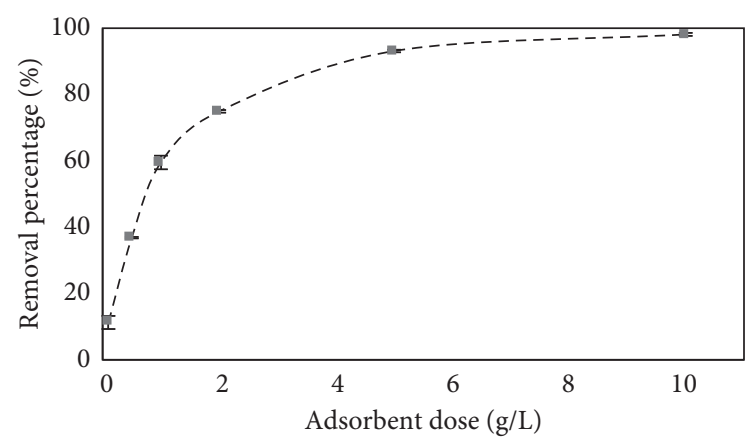

Figure 8: Effect of adsorbent dose on $\mathrm{Cr}(\mathrm{VI})$ ions removal from aqueous solution using WM adsorbent at $T=298(K), \mathrm{pH}=2$, time $=120 \mathrm{~min}$, and $[\mathrm{Cr}(\mathrm{VI})]=50 \mathrm{mg} / \mathrm{L}$.

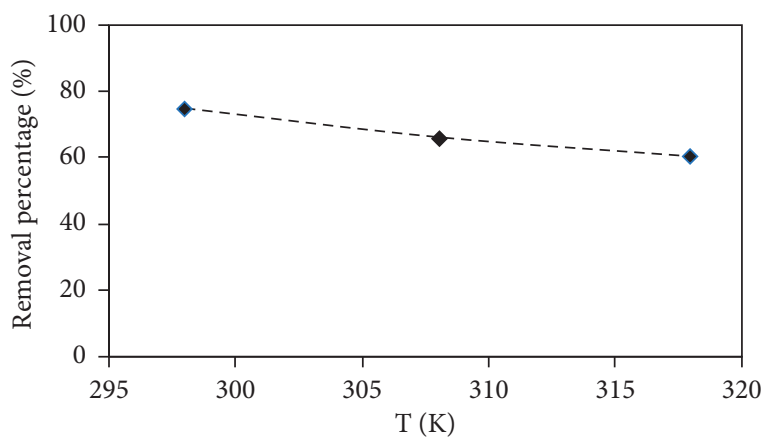

Figure 9: Effect of temperature on the adsorption of $\mathrm{Cr}$ (VI) from aqueous solution using $\mathrm{WM}$ adsorbent at $\mathrm{pH}=2$, time $=120 \mathrm{~min}$, adsorbent dose $W=2 \mathrm{~g} / \mathrm{L}$, and $[\mathrm{Cr}(\mathrm{VI})]=50 \mathrm{mg} / \mathrm{L}$.

$\mathrm{pH}$ of $2(74.9 \%)$. The adsorption capacity decreased with increasing temperature, suggesting that the adsorption process was exothermic.

3.3. Adsorption Kinetics. In order to define the adsorption kinetics of $\mathrm{Cr}(\mathrm{VI})$ by the WM adsorbent, the kinetic parameters of the adsorption process were studied for contact times varying from 0 to $120 \mathrm{~min}$ by controlling the concentration of $\mathrm{Cr}(\mathrm{VI})$ held in the filtrate. Figure 10 shows the adsorption kinetics curves for different initial concentrations of $\mathrm{Cr}(\mathrm{VI}): 10,20,30,40$, and $50 \mathrm{mg} / \mathrm{L}$.



FIgURE 10: Kinetics adsorption of $\mathrm{Cr}(\mathrm{VI})$ from aqueous solution using WM adsorbent at $\mathrm{pH}=2$, time $=120 \mathrm{~min}$, and adsorbent dose $W=2 \mathrm{~g} / \mathrm{L}$.

All kinetic parameters of $\mathrm{Cr}(\mathrm{VI})$ adsorption by WM are determined from the linear form of the model equations described in $[19,20]$.

The linear representations are shown in Figures 11-14, respectively.

To find the best fit kinetic model, the correlation coefficients $\left(R^{2}\right)$ of the different models were compared and are grouped in Table 2. However, $R^{2}$ correlation coefficients showed that the fractional power model fits better to the experimental data $\left(0.97 \leq R^{2} \leq 0.99\right)$ than the other models $\left(R^{2}\right.$ is in the range of $\left.0.24-0.99\right)$.

3.4. Adsorption Isotherms Studies. The isotherms study of $\mathrm{Cr}(\mathrm{VI})$ adsorption by the MW was carried out for 2 hours, with an initial $\mathrm{Cr}(\mathrm{VI}) \mathrm{C}_{0}$ concentration of $50 \mathrm{mg} / \mathrm{L}$ and a $\mathrm{pH}=2$, for different masses of the MW $(W=0.1,0.5,1$, and $2 \mathrm{~g} / \mathrm{L})$. The variation of the adsorption capacity $Q_{e}$ is related with the equilibrium concentration $C_{e}$. Several models were applied to describe the experimental data for the adsorption isotherms. The Freundlich and Langmuir models are the most frequently used. In the present work, four models were used and described in $[21,22]$. All parameters of the isotherms were determined from the linear relation (Figures 15-18) according to the equations of the models described in [21, 22].

The best-fit isotherms models were determined by calculating the determination coefficients $\left(R^{2}\right)$. Parameter values at $\mathrm{pH}=2$ for the maximum $\mathrm{Cr}(\mathrm{VI})$ adsorption by MW are reported in Table 3. From the values of the correlation coefficients, it can be concluded that the Langmuir model was best fitted to the experimental results of $\mathrm{Cr}(\mathrm{VI})$ adsorption by WM.

The essential characteristic parameter of the Langmuir isotherm can be expressed in terms of a dimensionless constant separation factor or also known as the equilibrium parameter $R_{L}$ [29]:

$$
R_{L}=\frac{1}{1+K_{L} \cdot C_{0}},
$$

where $K_{L}(\mathrm{~L} / \mathrm{mg})$ is the Langmuir constant and $C_{0}(\mathrm{mg} / \mathrm{L})$ is the initial concentration. $R_{L}=1$ represents linear adsorption, 




FIGURE 11: Linearity of the pseudo-first-order model.

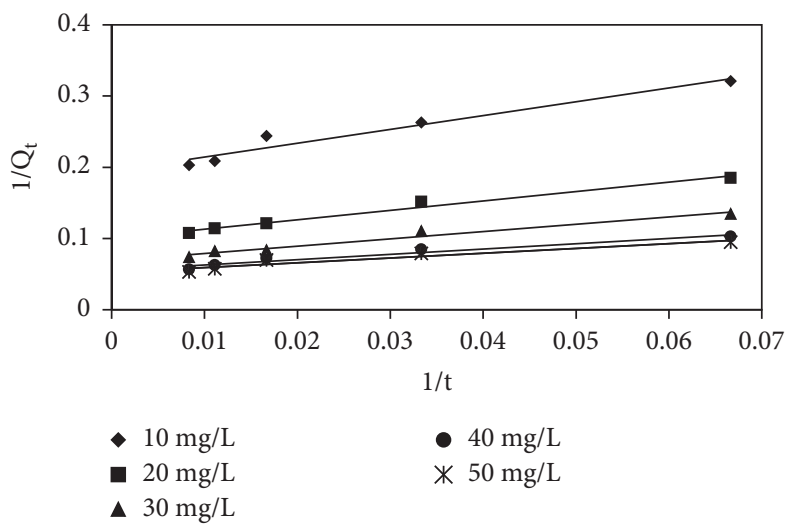

Figure 12: Linearity of the pseudo-second-order model.

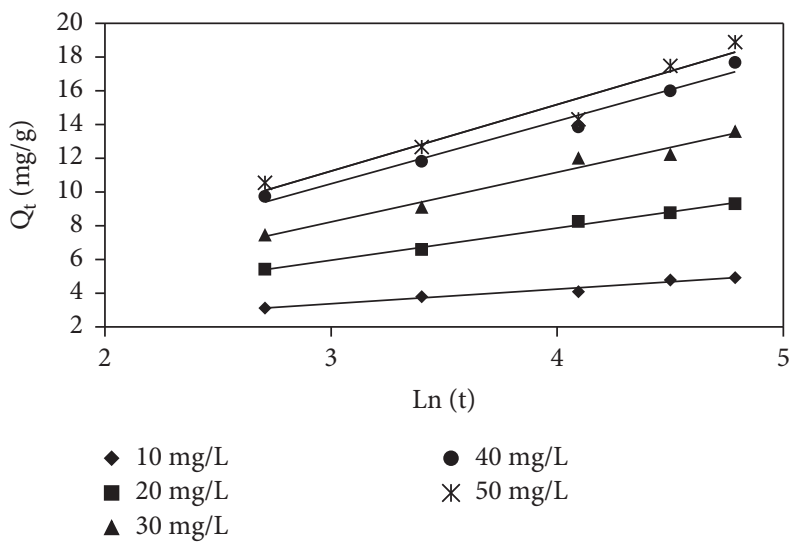

FIGURE 13: Linearity of Elovich model.

while $R_{L}=0$ stands for the irreversible adsorption process. $R_{L}<1$ is for favorable adsorption, while $R_{L}>1$ represents unfavorable adsorption. In this work, the value of $\mathrm{R}_{\mathrm{L}}$ was found to be 0.999 , suggesting that the equilibrium parameter was less than 1 but near to 1 , which means a favorable linear adsorption.
This means that the equilibrium isotherms can be well described by the Langmuir model (Figure 19), and the adsorption process takes place as a monolayer (ML) on a surface with a finite number of identical sites, which are distributed homogeneously over the surface of the adsorbent [30]. 


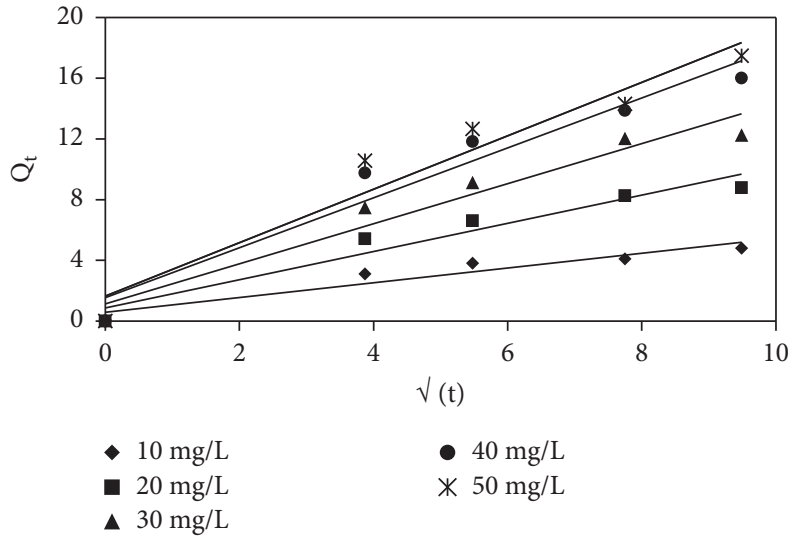

FIGURE 14: Linearity of intraparticle diffusion model.

TABLe 2: Adsorption kinetic model parameters at pH 2 for $\mathrm{Cr}(\mathrm{VI})$ removal.

\begin{tabular}{|c|c|c|c|c|c|c|}
\hline Model & Parameters & $C_{0}=10 \mathrm{mg} / \mathrm{L}$ & $C_{0}=20 \mathrm{mg} / \mathrm{L}$ & $C_{0}=30 \mathrm{mg} / \mathrm{L}$ & $C_{0}=40 \mathrm{mg} / \mathrm{L}$ & $C_{0}=50 \mathrm{mg} / \mathrm{L}$ \\
\hline \multirow{4}{*}{$\begin{array}{l}\text { Fractional } \\
\text { power }\end{array}$} & $\begin{array}{c}\text { Linear } \\
\text { expression }\end{array}$ & $y=0.217 x+0.560$ & $y=0.264 x+0.984$ & $y=0.289 x+1.233$ & $y=0.280 x+1.509$ & $y=0.276 x+1.592$ \\
\hline & & 0.97 & 0.98 & 0.97 & 0.99 & 0.97 \\
\hline & $\mathrm{k}_{\mathrm{p}}$ & 1.750 & 2.675 & 3.431 & 4.522 & 4.913 \\
\hline & $\Upsilon$ & 0.217 & 0.264 & 0.289 & 0.280 & 0.276 \\
\hline \multirow{4}{*}{$\begin{array}{l}\text { Pseudo-first- } \\
\text { order }\end{array}$} & $\begin{array}{l}\text { Linear } \\
\text { expression }\end{array}$ & $y=-0.035 x+1.398$ & $y=-0.030 x+1.994$ & $y=-0.025 x+2.335$ & $y=-0.023 x+2.634$ & $y=-0.025 x+2.739$ \\
\hline & $R^{2}$ & 0.93 & 0.97 & 0.92 & 0.95 & 0.93 \\
\hline & $\mathrm{k}_{1 \mathrm{P}}\left(\min ^{-1}\right)$ & 0.025 & 0.023 & 0.025 & 0.030 & 0.035 \\
\hline & $\mathrm{q}_{\mathrm{e} .1 \mathrm{P}}\left(\mathrm{mg} \cdot \mathrm{g}^{-1}\right)$ & 15.471 & 13.929 & 10.329 & 7.344 & 4.047 \\
\hline \multirow{4}{*}{$\begin{array}{l}\text { Pseudo- } \\
\text { second- } \\
\text { order }\end{array}$} & $\begin{array}{c}\text { Linear } \\
\text { expression }\end{array}$ & $y=1.940 x+0.195$ & $y=1.321 x+0.099$ & $y=1.025 x+0.068$ & $y=0.745 x+0.055$ & $y=0.672 x+0.052$ \\
\hline & & 0.95 & 0.98 & 0.96 & 0.94 & 0.91 \\
\hline & $\begin{array}{c}\mathrm{k}_{2 \mathrm{P}} \\
\left(\mathrm{g} \cdot \mathrm{mg}^{-1} \cdot \mathrm{min}^{-1}\right)\end{array}$ & 0.100 & 0.074 & 0.066 & 0.073 & 0.077 \\
\hline & $\mathrm{q}_{\mathrm{e} .2 \mathrm{P}}\left(\mathrm{mg} \cdot \mathrm{g}^{-1}\right)$ & 5.128 & 10.101 & 14.705 & 18.181 & 19.230 \\
\hline \multirow{4}{*}{ Elovich } & $\begin{array}{l}\text { Linear } \\
\text { expression }\end{array}$ & $y=0.866 x+0.772$ & $y=1.908 x+0,228$ & $y=2.942 x-0.603$ & $y=3.715 x-0.66$ & $y=3.947 x-0.603$ \\
\hline & $R^{2}$ & 0.96 & 0.99 & 0.97 & 0.97 & 0.95 \\
\hline & $\begin{array}{c}\alpha_{\mathrm{E}} \\
\left(\mathrm{mg} \cdot \mathrm{g}^{-1} \cdot \mathrm{min}^{-1}\right)\end{array}$ & 2.111 & 2.150 & 2.396 & 3.110 & 3.387 \\
\hline & $\beta_{\mathrm{E}}\left(\mathrm{g} \cdot \mathrm{mg}^{-1}\right)$ & 1.154 & 0.524 & 0.339 & 0.269 & 0.253 \\
\hline \multirow{4}{*}{$\begin{array}{l}\text { Intraparticle } \\
\text { diffusion }\end{array}$} & $\begin{array}{l}\text { Linear } \\
\text { expression }\end{array}$ & $y=0.253 x+2.248$ & $y=0.552 x+3.521$ & $y=0.853 x+4.458$ & $y=1.101 x+5.558$ & $y=1.176 x+5.948$ \\
\hline & $R^{2}$ & 0.96 & 0.96 & 0.95 & 0.99 & 0.98 \\
\hline & $\left(\mathrm{mg} \cdot \mathrm{g}^{-1} \cdot \mathrm{min}^{-1 /}\right)$ & 0.253 & 0.552 & 0.853 & 1.101 & 1.176 \\
\hline & $C_{\mathrm{D}}\left(\mathrm{mg} \cdot \mathrm{g}^{-1}\right)$ & 2.248 & 3.521 & 4.458 & 5.558 & 5.948 \\
\hline
\end{tabular}

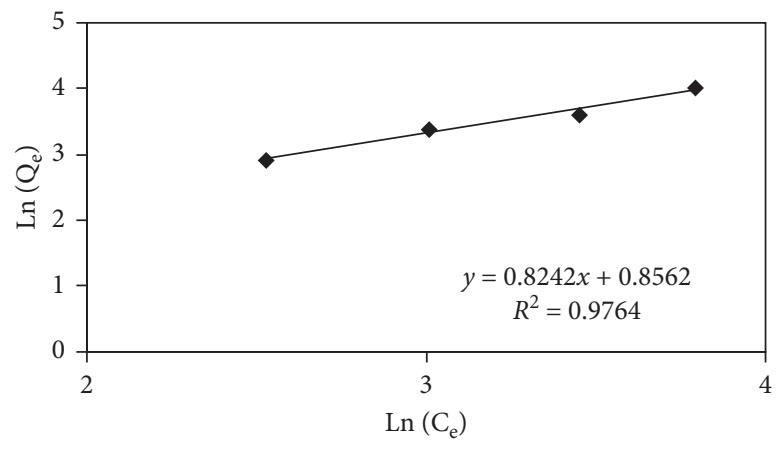

FIgURE 15: Linearity of Freundlich model. 


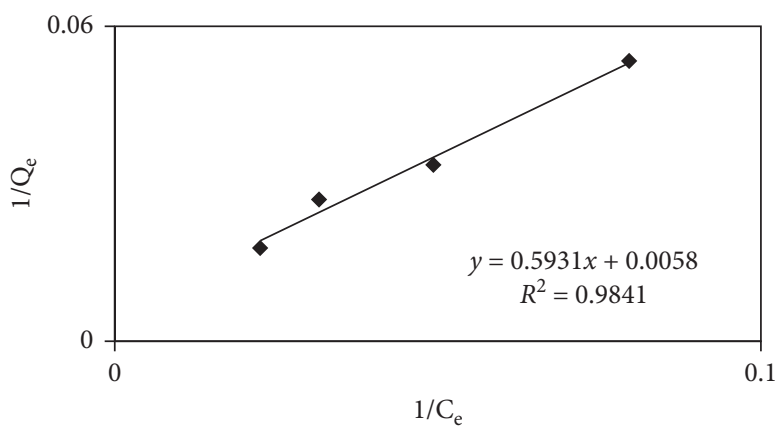

Figure 16: Linearity of Langmuir model.

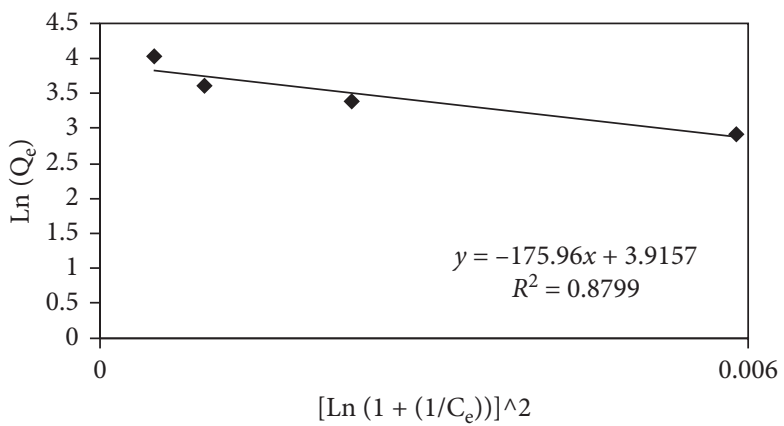

FIgURE 17: Linearity of $D-R$ model.

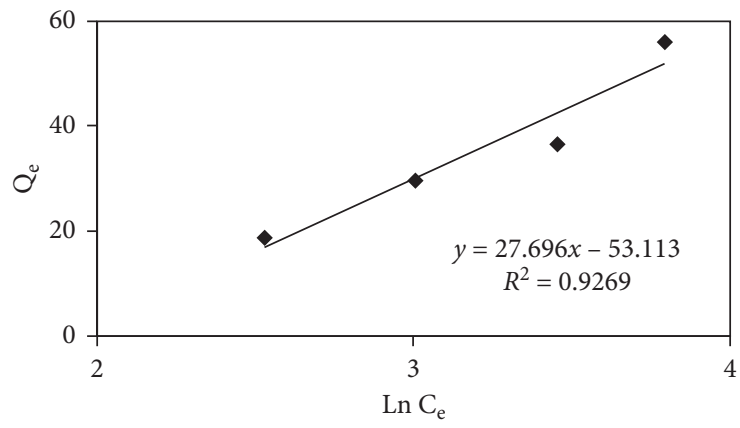

FIGURE 18: Linearity of Temkin model.

3.5. Thermodynamics Studies. The thermodynamic parameters of an adsorption process are necessary to decide whether the process is spontaneous or not. Experimental data obtained at different temperatures were used to calculate thermodynamic parameters such as Gibbs-free energy change $\left(\Delta G^{\circ}\right)$, enthalpy change $\left(\Delta H^{\circ}\right)$, and entropy change $\left(\Delta S^{\circ}\right)$. The Gibbsfree energy changes in the sorption reaction are given by equations (3)-(5), where $K=K_{L}$ is the equilibrium constant, which can be obtained from the Langmuir isotherm at different temperatures. $\Delta H^{\circ}$ and $\Delta S^{\circ}$ were obtained from the slope and intercept of the plot of $\ln K_{L}$ vs. $1 / T$ (Figure 20). The calculated results are reported in Table 4.

The negative values of $\Delta G^{\circ}$ confirm the feasibility of the process and the spontaneous nature of adsorption. The standard enthalpy and entropy changes in adsorption determined from Figure 20 were $-28.93 \mathrm{~kJ} / \mathrm{mol}$ and $-0.081 \mathrm{~kJ} / \mathrm{k} . \mathrm{mol}$, respectively, with a correlation coefficient of 0.96 . The value of $\Delta H^{\circ}$ is negative, indicating that the adsorption reaction is exothermic. The negative value of $\Delta S^{\circ}$ reflects a decrease in the randomness at the solid/solution interface during the adsorption process [31].

3.6. Mechanism of Adsorption by FTIR. The FTIR spectra before and after the adsorption of $\mathrm{Cr}(\mathrm{VI})$ by WM are shown in Figure 19. For the spectrum obtained after the adsorption of hexavalent chromium, there is a remarkable change in the intensities of the infrared bands without any change in position. The characterization by infrared spectroscopy also made it possible to confirm the results obtained by other methods of investigation. The structural properties of the adsorbent 
TABLE 3: Adsorption isotherms models parameter at $\mathrm{pH} 2$ for $\mathrm{Cr}(\mathrm{VI})$ adsorption by WM.

\begin{tabular}{|c|c|c|}
\hline Model & Model parameters & Values of parameters \\
\hline Freundlich & $\begin{array}{c}\text { Linear expression } \\
R^{2} \\
K_{F}(\mathrm{~L} / \mathrm{g}) \\
n_{F}\end{array}$ & $\begin{array}{c}y=0.824+0.856 \\
0.97 \\
2.354 \\
0.824\end{array}$ \\
\hline Langmuir & $\begin{array}{c}\text { Linear expression } \\
R^{2} \\
K_{L}(\mathrm{~L} / \mathrm{g}) \\
q_{m . L}(\mathrm{mg} / \mathrm{g}) \\
R_{L} \\
\end{array}$ & $\begin{array}{c}y=0.593 x+0.005 \\
0.98 \\
0.009 \\
172.410 \\
0.999\end{array}$ \\
\hline D-R & $\begin{array}{c}\text { Linear expression } \\
R^{2} \\
E(\mathrm{~J} / \mathrm{mol}) \\
q_{m, \mathrm{DR}}(\mathrm{mg} / \mathrm{g})\end{array}$ & $\begin{array}{c}y=-175.960 x+3.915 \\
0.87 \\
186.770 \\
50.180\end{array}$ \\
\hline Temkin & $\begin{array}{c}\text { Linear expression } \\
R^{2} \\
K_{T}(\mathrm{~L} / \mathrm{g}) \\
B_{T}(\mathrm{~J} / \mathrm{mol})\end{array}$ & $\begin{array}{c}y=27.690 x-53.113 \\
0.92 \\
0.146 \\
27.690\end{array}$ \\
\hline
\end{tabular}



FIGURE 19: Modeling of the isotherm adsorption by Langmuir model.



FIGURE 20: FTIR spectra of WM before and after adsorption.

determine the effect of the degree of impregnation on the pore type distribution and the pore structure of the adsorbent. It has been determined that vigorous stimulation promotes pore formation at this level [32].
3.7. Comparison of $\mathrm{Cr}(\mathrm{VI})$ Adsorption Capacity of Different Adsorbents. The adsorption capacity of the different $\mathrm{Cr}(\mathrm{VI})$ adsorbents previously studied in the bibliography was compared with the current results, as shown in Table 5. It 
TABLE 4: Thermodynamic parameters of adsorption of $\mathrm{Cr}(\mathrm{VI})$ on the WM.

\begin{tabular}{|c|c|c|c|c|}
\hline \multirow{2}{*}{$\Delta \mathrm{H}^{\circ}(\mathrm{KJ} / \mathrm{mol})$} & \multirow{2}{*}{$\Delta S^{\circ}(\mathrm{KJ} / \mathrm{K} . \mathrm{mol})$} & \multicolumn{3}{|c|}{$\Delta \mathrm{G}^{\circ}(\mathrm{KJ} / \mathrm{mol})$} \\
\hline & & $298 \mathrm{~K}$ & $308 \mathrm{~K}$ & $318 \mathrm{~K}$ \\
\hline-28.93 & -0.081 & -4.83 & -4.02 & -3.22 \\
\hline
\end{tabular}

TABLE 5: Comparison of adsorption capacities of WM with other adsorbents for $\mathrm{Cr}(\mathrm{VI})$.

\begin{tabular}{|c|c|c|c|c|}
\hline No. & Adsorbent & $Q_{\max }(\mathrm{mg} / \mathrm{g})$ & $\mathrm{pH}$ & Ref. \\
\hline 1 & Modified rice husk & 278 & 2 & {$[33]$} \\
\hline 2 & Mosambi (Citrus limetta) peel & 250 & 2 & {$[34]$} \\
\hline 3 & Modified groundnut shell & 131 & 2 & {$[35]$} \\
\hline 4 & Chrysophyllum albidum (Sapotaceae) seed shells & 84.31 & 3 & {$[36]$} \\
\hline 5 & Treated waste newspaper & 59.88 & 3 & {$[37]$. } \\
\hline 6 & Guar gum-nano-zinc oxide & 55.56 & 7 & {$[38]$} \\
\hline 7 & Rice husk carbon & 47.61 & 2 & [39] \\
\hline 8 & Eucalyptus bark & 45 & 2 & {$[40]$} \\
\hline 9 & Wool & 41.15 & 2 & {$[41]$} \\
\hline 10 & Olive cake & 33.44 & 2 & {$[42]$} \\
\hline 11 & Chitosan-coated fly ash & 33.27 & 5 & [43] \\
\hline 12 & Modified seaweed (Bifurcaria bifurcata) & 29.29 & 5.8 & {$[18]$} \\
\hline 13 & Plantain waste & 16.1 & & {$[44]$} \\
\hline 14 & Saw dust & 15.82 & 2 & {$[45]$} \\
\hline 15 & Almond & 10.61 & 2 & {$[46]$} \\
\hline 16 & Banana (Musa Lacatan) waste & 10 & 2 & {$[47]$} \\
\hline 17 & Tea (Camellia sinensis) waste & 7.29 & 2 & {$[42]$} \\
\hline 18 & Pine needles & 7.08 & 2 & {$[48]$} \\
\hline 19 & Peels of pea (Pisum sativum) pod & 4.33 & 2 & {$[49]$} \\
\hline 20 & Waste of mint (Mentha spicata) & 172 & 2 & This work \\
\hline
\end{tabular}

can be observed that the maximum adsorption capacity $\left(Q_{\max }\right)$, at $\mathrm{pH}=2$, is higher $(172 \mathrm{mg} / \mathrm{g}$ for the WM) than the most recently reported adsorbents. This result indicates that the waste mint applied in this study is a better alternative to other low-cost adsorbents. However, higher adsorption capacities of 250 and $278 \mathrm{mg} / \mathrm{g}$ were reported for modified rice husk and mosambi (Citrus limetta) peel at the same $\mathrm{pH}$, respectively.

\section{Conclusion}

Removal of $\mathrm{Cr}$ (VI) from wastewater is possible using several abundantly available low-cost adsorbents. The present investigation showed that the WM is an effective adsorbent for the removal of chromium(VI) from aqueous solutions. The WM was characterized using SEM, FTIR, TGA, and DSC analysis. The effects of $\mathrm{pH}$, initial concentration of $\mathrm{Cr}(\mathrm{VI})$, and adsorbent dose and temperature, on adsorption were investigated. The adsorption decreased with increasing $\mathrm{pH}$, initial concentration of $\mathrm{Cr}(\mathrm{VI})$, and temperature, while it increased with increasing adsorbent dose. The kinetic data followed the fractional power kinetic model. The isotherm data were analyzed by Freundlich, Langmuir, $D-R$, and Temkin isotherms, and the data fitted the Langmuir model better than the other models. The maximum monolayer coverage adsorption capacity from the Langmuir isotherm model was $172 \mathrm{mg} / \mathrm{g}$. The thermodynamics parameters were calculated: the negative values of $\Delta G^{\circ}$ indicate the spontaneous nature of the adsorption process, and the negative values of $\Delta H^{\circ}$ indicate the exothermic nature of the adsorption. Finally, the FTIR results suggested that the adsorption of $\mathrm{Cr}(\mathrm{VI})$ on the WM was mechanical entrapment.

\section{Data Availability}

The data used to support the findings of this study are included within the article.

\section{Conflicts of Interest}

The authors declare that they have no conflicts of interest.

\section{References}

[1] A. Ainane, F. Khammour, E. L. M'hammed et al., "Evaluation of the toxicity of the essential oils of certain mints grown in the region of settat (Morocco): mentha piperita, mentha pulegium and mentha spicata against, sitophilus granarius, sitophilus oryzae and sitophilus zeamais," Journal of Analytical Sciences and Applied Biotechnology, vol. 1, no. 4, 2019.

[2] H. Sarma, S. Sonowal, and M. N. V. Prasad, "Plant-microbiome assisted and biochar-amended remediation of heavy metals and polyaromatic compounds - a microcosmic study," Ecotoxicology and Environmental Safety, vol. 176, pp. 288299, 2019. 
[3] S. S. Dhaliwal, J. Singh, P. K. Taneja, and A. Mandal, "Remediation techniques for removal of heavy metals from the soil contaminated through different sources: a review," Environmental Science and Pollution Research, vol. 27, no. 2, pp. 1319-1333, 2020.

[4] P. K. Rai, S. S. Lee, M. Zhang, Y. F. Tsang, and K.-H. Kim, "Heavy metals in food crops: health risks, fate, mechanisms, and management," Environment International, vol. 125, pp. 365-385, 2019.

[5] B. Moine, C. Chan Peng, and A. Mercier, "Rôle du fluor dans la formation des gisements d'émeraude de Mananjary (Est de Madagascar)," Comptes Rendus Geoscience, vol. 336, no. 6, pp. 513-522, 2004.

[6] L. Ghafoor, M. Boutahala, and B. Djellouli, "Étude de l'élimination du Cr (VI) par l'oxyde mixte obtenu par calcination de l'hydroxyde double lamellaire MgAl," Comptes Rendus Chimie, vol. 17, no. 7-8, pp. 860-868, 2014.

[7] R. Nowruzi, M. Heydari, and V. Javanbakht, "Synthesis of a chitosan/polyvinyl alcohol/activate carbon biocomposite for removal of hexavalent chromium from aqueous solution," International Journal of Biological Macromolecules, vol. 147, pp. 209-216, 2020.

[8] H. Deng, L. Yang, Y. Li et al., "Environmental occurrence and risk assessment of haloacetic acids in swimming pool water and drinking water," RSC Advances, vol. 10, no. 47, pp. 28267-28276, 2020.

[9] G. Crini and E. Lichtfouse, "Advantages and disadvantages of techniques used for wastewater treatment," Environmental Chemistry Letters, vol. 17, no. 1, pp. 145-155, 2019.

[10] Y. Cao, W. Fan, T. Zhou, and X. Li, "Removal of chelated heavy metals from aqueous solution: a review of current methods and mechanisms," Science of The Total Environment, vol. 678, pp. 253-266, 2019.

[11] N. H. Abdullah, K. Shameli, E. C. Abdullah, and L. C. Abdullah, "Solid matrices for fabrication of magnetic iron oxide nanocomposites: synthesis, properties, and application for the adsorption of heavy metal ions and dyes," Composites Part B: Engineering, vol. 162, pp. 538-568, 2019.

[12] L. Y. Li, X. Gong, and O. Abida, "Waste-to-resources: exploratory surface modification of sludge-based activated carbon by nitric acid for heavy metal adsorption," Waste Management, vol. 87, pp. 375-386, 2019.

[13] P. Racho and W. Waiwong, "Modified textile waste for heavy metals removal," Energy Reports, vol. 6, pp. 927-932, 2020.

[14] S. Sangkarak, A. Phetrak, S. Kittipongvises, D. Kitkaew, D. Phihusut, and J. Lohwacharin, "Adsorptive performance of activated carbon reused from household drinking water filter for hexavalent chromium-contaminated water," Journal of Environmental Management, vol. 272, Article ID 111085, 2020.

[15] N. K. Soliman and A. F. Moustafa, "Industrial solid waste for heavy metals adsorption features and challenges; a review," Journal of Materials Research and Technology, vol. 9, no. 5, pp. 10235-10253, 2020.

[16] G. L. Sun, E. E. Reynolds, and A. M. Belcher, "Designing yeast as plant-like hyperaccumulators for heavy metals," Nature Communications, vol. 10, no. 1, pp. 1-12, 2019.

[17] N. Saranya, E. Nakeeran, M. S. Giri Nandagopal, and N. Selvaraju, "Optimization of adsorption process parameters by response surface methodology for hexavalent chromium removal from aqueous solutions using Annona reticulata Linn peel microparticles," Water Science and Technology, vol. 75, no. 9, pp. 2094-2107, 2017.

[18] T. Ainane, A. Abourriche, M. Kabbaj et al., "Removal of hexavalent chromium from aqueous solution by raw and chemically modified seaweed Bifurcaria bifurcata," Journal of Materials and Environmental Science, vol. 5, no. 4, pp. 975982, 2014

[19] F. Gündüz and B. Bayrak, "Biosorption of malachite green from an aqueous solution using pomegranate peel: equilibrium modelling, kinetic and thermodynamic studies," Journal of Molecular Liquids, vol. 243, pp. 790-798, 2017.

[20] S. S. Madan, K. L. Wasewar, and C. Ravi Kumar, "Adsorption kinetics, thermodynamics, and equilibrium of $\alpha$-toluic acid onto calcium peroxide nanoparticles," Advanced Powder Technology, vol. 27, no. 5, pp. 2112-2120, 2016.

[21] R. Ahmad and K. Ansari, "Polyacrylamide-Grafted Actinidia deliciosa peels powder (PGADP) for the sequestration of crystal violet dye: isotherms, kinetics and thermodynamic studies," Applied Water Science, vol. 10, no. 8, pp. 1-15, 2020.

[22] K. C. Nebaghe, Y. El Boundati, K. Ziat, A. Naji, L. Rghioui, and M. Saidi, "Comparison of linear and non-linear method for determination of optimum equilibrium isotherm for adsorption of copper (II) onto treated Martil sand," Fluid Phase Equilibria, vol. 430, pp. 188-194, 2016.

[23] M. Ghasemi, H. Javadian, N. Ghasemi, S. Agarwal, and V. K. Gupta, "Microporous nanocrystalline NaA zeolite prepared by microwave assisted hydrothermal method and determination of kinetic, isotherm and thermodynamic parameters of the batch sorption of Ni (II)," Journal of Molecular Liquids, vol. 215, pp. 161-169, 2016.

[24] J. Gaitán-Alvarez, A. Berrocal, G. I. Mantanis, R. Moya, and F. Araya, "Acetylation of tropical hardwood species from forest plantations in Costa Rica: an FTIR spectroscopic analysis," Journal of Wood Science, vol. 66, no. 1, pp. 1-10, 2020.

[25] J. Guo, X. Chen, J. Wang, Y. He, H. Xie, and Q. Zheng, "The influence of compatibility on the structure and properties of PLA/lignin biocomposites by chemical modification," Polymers, vol. 12, no. 1, 56 pages, 2020.

[26] X. Zhang, J. Gao, S. Zhao et al., "Hexavalent chromium removal from aqueous solution by adsorption on modified zeolites coated with Mg-layered double hydroxides," Environmental Science and Pollution Research, vol. 26, no. 32, pp. 32928-32941, 2019.

[27] S. I. Rathnayake, W. N. Martens, Y. Xi, R. L. Frost, and G. A. Ayoko, "Remediation of Cr (VI) by inorganic-organic clay," Journal of Colloid and Interface Science, vol. 490, pp. 163-173, 2017.

[28] X.-Z. Wei, Z.-Q. Gan, Y.-J. Shen, Z.-L. Qiu, L.-F. Fang, and B.-K. Zhu, "Negatively-charged nanofiltration membrane and its hexavalent chromium removal performance," Journal of Colloid and Interface Science, vol. 553, pp. 475-483, 2019.

[29] T. N. Hai, S. J. You, and H. P. Chao, "Adsorption capacity and mechanism of cadmium on orange peel-derived biochar at different pyrolysis temperatures and times," Journal of Solid Waste Technology \& Management, vol. 42, no. 1, 2016.

[30] Y. Tang, Z. Li, Z. Xu, J. Zhang, C. Qu, and Z. Zhang, "Synthesis of hierarchical $\mathrm{MgO}$ based on a cotton template and its adsorption properties for efficient treatment of oilfield wastewater," RSC Advances, vol. 10, no. 48, pp. 28695-28704, 2020.

[31] M. N. Sahmoune, "Evaluation of thermodynamic parameters for adsorption of heavy metals by green adsorbents," Environmental Chemistry Letters, vol. 17, no. 2, pp. 697-704, 2019.

[32] Z. Anfar, A. Amedlous, M. Majdoub et al., "New amino group functionalized porous carbon for strong chelation ability towards toxic heavy metals," RSC Advances, vol. 10, no. 52, pp. 31087-31100, 2020.

[33] E. I. El-Shafey, "Behaviour of reduction-sorption of chromium (VI) from an aqueous solution on a modified sorbent 
from rice husk," Water, Air, and Soil Pollution, vol. 163, no. 14, pp. 81-102, 2005.

[34] R. Saha, K. Mukherjee, I. Saha, A. Ghosh, S. K. Ghosh, and B. Saha, "Removal of hexavalent chromium from water by adsorption on mosambi (Citrus limetta) peel," Research on Chemical Intermediates, vol. 39, no. 5, pp. 2245-2257, 2013.

[35] S. O. Owalude and A. C. Tella, "Removal of hexavalent chromium from aqueous solutions by adsorption on modified groundnut hull," Beni-suef University Journal of Basic and Applied Sciences, vol. 5, no. 4, pp. 377-388, 2016.

[36] E. Nakkeeran, S. Rangabhashiyam, M. S. Giri Nandagopal, and N. Selvaraju, "Removal of Cr (VI) from aqueous solution using Strychnos nux-vomica shell as an adsorbent," Desalination and Water Treatment, vol. 57, no. 50, pp. 23951-23964, 2016.

[37] D. C. Sharma and C. F. Forster, "A preliminary examination into the adsorption of hexavalent chromium using low-cost adsorbents," Bioresource Technology, vol. 47, no. 3, pp. 257-264, 1994.

[38] Q. Wang, H. Qian, Y. Yang, Z. Zhang, C. Naman, and X. Xu, "Reduction of hexavalent chromium by carboxymethyl cellulose-stabilized zero-valent iron nanoparticles," Journal of Contaminant Hydrology, vol. 114, no. 4, pp. 35-42, 2010.

[39] N. R. Bishnoi, M. Bajaj, N. Sharma, and A. Gupta, "Adsorption of $\mathrm{Cr}$ (VI) on activated rice husk carbon and activated alumina," Bioresource Technology, vol. 91, no. 3, pp. 305-307, 2004.

[40] V. Sarin and K. Pant, "Removal of chromium from industrial waste by using eucalyptus bark," Bioresource Technology, vol. 97, no. 1, pp. 15-20, 2006.

[41] M. Owlad, M. K. Aroua, W. A. W. Daud, and S. Baroutian, "Removal of hexavalent chromium-contaminated water and wastewater: a review," Water, Air, and Soil Pollution, vol. 200, no. 4, pp. 59-77, 2009.

[42] E. Malkoc, Y. Nuhoglu, and M. Dundar, "Adsorption of chromium (VI) on pomace-An olive oil industry waste: batch and column studies," Journal of Hazardous Materials, vol. 138, no. 1, pp. 142-151, 2006.

[43] Y. Wen, Z. Tang, Y. Chen, and Y. Gu, "Adsorption of Cr (VI) from aqueous solutions using chitosan-coated fly ash composite as biosorbent," Chemical Engineering Journal, vol. 175, pp. 110-116, 2011.

[44] S. O. Idowu, S. O. Oni, and A. A. Adejumo, "Biosorption of chromium (VI) from aqueous solution by biomass of plantain (musa paradisiaca) peel residue," African Journal of Medical Physics, Biomedical Engineering, vol. 3, pp. 22-30, 2011.

[45] S. S. Baral, S. N. Das, and P. Rath, "Hexavalent chromium removal from aqueous solution by adsorption on treated sawdust," Biochemical Engineering Journal, vol. 31, no. 3, pp. 216-222, 2006.

[46] E. Pehlivan and T. Altun, "Biosorption of chromium (VI) ion from aqueous solutions using walnut, hazelnut and almond shell," Journal of Hazardous Materials, vol. 155, no. 2, pp. 378-384, 2008.

[47] P. K. Sharma, S. Ayub, and C. N. Tripathi, "Isotherms describing physical adsorption of $\mathrm{Cr}$ (VI) from aqueous solution using various agricultural wastes as adsorbents," Cogent Engineering, vol. 3, no. 1, Article ID 1186857, 2016.

[48] D. Park, S.-R. Lim, Y.-S. Yun, and J. M. Park, "Reliable evidences that the removal mechanism of hexavalent chromium by natural biomaterials is adsorption-coupled reduction," Chemosphere, vol. 70, no. 2, pp. 298-305, 2007.

[49] J. El Alem, U. Shafique, U. Z. Waheed et al., "Removal of chromium from water using pea waste - a green approach,"
Green Chemistry Letters and Reviews, vol. 3, no. 3, pp. 239-243. 